Hudson River to her pier in New York Harbour on the completion of her voyage on Monday, June 1. The thrilling scenes which accompanied the superb reception given by the hundreds of thousands of spectators were described by commentators at various vantage points, such as the quay front, a tug accompanying the giant liner, an aeroplane flying overhead and a special announcer located seventy stories up on the Radio City building. Since much of this programme had to be relayed over two or more radio links with the intermediate land-line connexions, the high average standard of the broadcasts illustrates the tremendous possibilities which result from the modern technique and organisation of this branch of communications engineering.

\section{Anniversary of Marconi's First Patent}

Forty years ago on June 2, Marconi filed the application for his first patent for a wireless invention. That patent-No. 12039 of 1896 -described the use of Marconi's sensitive tube receiver, or coherer, connected to an earth and elevated aerial and the tuning of the transmitting and receiving circuits with each other. Since that time nearly 800 patents have either been granted to Marconi and the Marconi companies, or are pending, for the inventions and developments in wireless telegraphy and telephony and broadcasting. The first British ship was equipped with Marconi apparatus in 1901. To-day, more than 3,000 British ships carry Marconi wireless installations, and thousands of people owe their lives to its use. Wireless messages were exchanged between England and Canada in 1902, and a public service was opened in 1907. For direct transmission by the long-wave system the estimated power to the aerial amounted to something like 1,000 kilowatts, the stations were to cost more than $£ 1,000,000$ each, the wave-lengths were to be of the order of 18 miles, and the aerials were to be carried on towers about 800 feet high. These figures now seem fantastic. As the result of a series of tests between the experimental station at Poldhu and Marconi's yacht Elettra, in 1923 and 1924, the short-wave beam system was evolved which enabled the Marconi Company to make an offer to the Post Office to establish communication with the Dominions using a fiftieth of the power, involving a twentieth of the cost, and providing a speed of working at least three times as great as that which was possible with the earlier long-wave system of communication. Experiments in telephony by wireless were first carried out by the Marconi Company in 1906, and it is claimed that there are now 180 Marconi broadcasting stations in use in 32 countries. It is estimated that the wireless industry employs 50,000 workpeople in Great Britain, and that the British radio industry alone has a turnover of $£ 30,000,000$ per annum.

\section{Z0o: A New Periodical}

THE Zoological Society of London has begun a venture which rounds off its benefactions to the nation. For well over a century its collections have amused and instructed the general public, it has spent vast sums upon the publication of scientific papers for the learned, and now in a popular monthly magazine it proposes to bring the interest of the zoo to those who cannot visit the enclosures, and generally to diffuse a knowledge of animals and their ways. Britain has lagged far behind the United States in the production of high-class popular magazines of science: we know nothing that can compare with Natural History, the journal of the American Museum of Natural History. But Zoo, in the quality of its text and in the interest and character of its illustrations, comes near to the American standard, and from the popular view it has gone one better, in leaving the stricter path of knowledge and introducing lighter stories of wild life. Many of the articles in the first number are by well-known scientific workers, and it is a pleasure to see that they possess the art of driving the pen so that the plain man can read.

\section{Cultivation of Cherries and Soft Fruits}

THe healthy and expanding state of the fruit. growing industry in Great Britain is evident from the Royal Horticultural Society's report on the con. ference on cherries and soft fruits held in July last. This follows a similar report of the conference on apples and pears held in 1934. The chairman, Sir Daniel Hall, expressed the opinion in his opening address that no other branch of agriculture has profited so much from the findings of research, and this close connexion between the industry and the various research institutions is fully borne out by the papers read at the conference. These are con. tributed equally by officers of the research stations and commercial fruit growers, and display a close co-ordination between the two points of view. The subjects dealt with embrace every aspect of the soft fruit industry, particular attention being devoted to cultural problems and the control of pests and diseases, whilst extensive data are presented concerm. ing manurial treatment and the effects of certain mineral deficiencies. A symposium on strawberry cultivation indicates the widespread interest in this fruit and the anxiety of both growers and research workers to deal with the numerous pests which have depleted the crop in recent years. Much information is given regarding the characteristics of varieties of cherries, raspberries and loganberries, and the qualities of fruit required for canning and bottling are also discussed. Copies of the report, price 6s., may be had from the Royal Horticultural Society, Vincent Square, S.W.1.

\section{Greenkeeping Research}

EVERY question connected with turf production and maintenance comes under review at the St. Ives Research Station, Bingley, Yorks, and a perusal of the Report for 1935 published by the Board of Green. keeping Research shows how rapidly both the experimental and advisory work have developed since the Station was founded in 1929. The bulk of the monery required to finance the work is subscribed by British golf clubs through the national unions. Free postal 